\title{
UNDERPINNING NEW ZEALAND'S PSYCHIC PREMIUM
}

\author{
B.R. RICHARDS \\ P.O. Box 28032, Auckland
}

\begin{abstract}
We broke away and drifted silently from Gondwanaland 80 Million years ago. Moving steadily into the Pacific and warming up. Like an Ark, we carried a manifest of old plants and animals to the present day. Our time warp meant our primitive Gondwana flora and fauna, were not so overwhelmed by the rapid expansion of flowering plants and mammals, as they were on more significant land masses of the world. We took our own course, we broke ties with the rest of the globe, we evolved differently. Those in the Ark had to adapt to the changes or die, there was no way out. Aotearoa New Zealand was as much an island prison as an island paradise.

The early people, both Maori and Pakeha, were as much the flightless birds, struggling for their survival, as were the Kakapo and Kiwi, also marooned many thousands of years before them. No one: plant, flightless bird, frog or human being, has ever held a return ticket, when starting out in this place. And the journey, in surviving and adapting here in New Zealand, continues even today.

My questions are:Will we have as much vision to set off into the new century, as our early people did coming into this one? Where does this vision begin? not in boardrooms or conferences, its more a spiritual thing, some self-reflection, a sense of history and time, pastechoes.

There have been several descriptions of Aotearoa; many years ago, Rudyard Kipling called it: "Last, loveliest, loneliest land apart". Somewhere along the way, the name "God's Own" was bestowed and accepted.

'Land of the Long White Cloud'.

'Gem of the South Pacific'.
\end{abstract}

This is a land, that for most of its history, has dominated its inhabitants. Its backbone was high, strong and forbidding. Its rivers crashed through canyons and exploded in flood ... and at its centre, it was a living thing. Great eruptions and their legacy of lakes and streams and uncertainty are with us even now.

Our macho busyness leaves us little time to reflect on such things. We have to deal with the now and while we rush through boardrooms and airports in this current national dementia, our curators and cultural archivists continue in their failure to relate on such issues. They fail to see their ability to contribute so much, to explain simply the art-forms, their stories. To fill a lonely manager's soul with another dimension, a sense of history and time, laughter, softness, even craziness and impermanence. You see, its this vacuum in our souls, when better filled, that will eventually produce a Vision for New Zealand, our Aotearoa.

A contentedness arising from;

who we are?

where do we all come from?

and what we are about?

James K. Baxter wrote so beautifully in the 1960's: “These unshaped Islands on the sawyer's bench, wait for the chisel of the mind!" ... and it seems, after thirty years, it's still the case in so many things. Many New Zealanders still think that our wealth comes from the pasture or off the hoof, rather than between the ears. New Zealand's economic position has been gently sliding backwards, since the sixties, as third world nations trade increasingly in our type of commodities: cheap meat, cheap holidays, cheap fish.

Our response is to throw on more fertiliser, build more efficient meat-works, get a bigger fishing boat, push more people down the Milford Track. Just more of the same for less revenue. Running faster and faster to maintain our position. There is no more land

Proc. 50th N.Z. Plant Protection Conf. 1997: 1-5 
to mine. In some parts of New Zealand, we have mined too much and its disappearing out to sea.

We now, for the first time, in our history, as an abundant Nation, have to learn, how to sell less for more. Our future prosperity will depend on the quality and quantity of our ideas and whether we have the capacity to turn these ideas into wealth generating products and services. We would all like to think, this is the debutante decade for Aotearoa New Zealand. That we will reach bi-culturalism, add lots of value, take our place in a peaceful Pacific.

We want new thinking, local thinking, home based, well focused with a frank admittance and a call for help. Help us see the living natural history around us, our precious environment, its values. Communicating this excitement, the quality and uniqueness of New Zealand is a task which has confronted and confounded the Nation for many years.

We need to discover thepsychic premium of New Zealand and learn to package it in our products and services. As probably one of the more unique "Water Nations" of the world, we have no Inland People, Mountain Tribes or the like. Our sense of inquisitiveness and discovery made all of us brave dangerous waters to come here and now, to make it better, we have to brave them again, this time in the international market place. Without soul and a spiritual togetherness, we have little chance of success. It is about creating wealth, the difference for me, being a moral and lifestyle wealth, as well as an economic one.

These unique trade-offs have little international parallel - if we can energise enough New Zealander's to care, then a blend of endeavours can deliver it - and we can sell it. It is not so much about: What it is?

It is more about; the magic of this place perhaps?

Why it tastes so good?

The beliefs of the people, who made the product or provide the service. The rare, rare pleasure of it all.

Getting into a boardroom with these thoughts is often difficult. You can't see them, so the Engineer says ... 'bunkum'. You can't measure them, so the Accountant dismisses them. Its 'woolly woofter country'.

A world of design, story telling, product positioning, values, intellectual know-how, a sense of place. Its a very squishy subject and for most, its too hard. And yet, why is it, when I go to buy Yoghurt ... the names of "Yoplait" or "Gervais" appear on the containers. Royalty arrangements with French companies, where the real margins are and yet the product is made from rich New Zealand land and processed with world leading technology in the Waikato.

\section{A Debutante Decade or are we kidding ourselves?}

Any amount of money, machinery and deal making is not enough. Too many of our products and services are old fashioned, poorly presented, lacking service values, making premiums for them impossible. Without new insights, without a new kind of thinking, we will never give birth to world beating products. Do we, as New Zealanders, have the skills to sell less for more?

The most important assets of any business are intangible. The company name, the symbols and product story, their underlying associations, perceived quality, name awareness, customer base and proprietary items, such as patents, trademarks and distribution relationships.

These intangible assets are the primary source of competitive advantage. They are the Brand Story! Brands will become increasingly important to both marketers and consumers in the 90 s, as functional product differences become ever more trivial. Within that, the softer side of Brands, personality, image, relationships will actually become the cutting edge of Brand distinction.

For years New Zealand's land based businesses have promoted themselves in generic ways. Most have failed to protect themselves and a great deal of promotional money has been wasted. We have advertised for example 'Kiwifruit', 'Canterbury Lamb', 'Merino Wool', consuming millions of levied dollars and failed to register them as Brands. The 
quality story we pushed has been borrowed, abused and debased by many players, who are happy to enjoy the umbrella story, but are not interested in reaching the quality thresholds.

Over the years, the NZ Meat Producers Board's Rosette has quietly floated back to simply a state of origin mark with little more value. Many players use it without approval and the industry still can't agree on lifting it to a serious endorsed mark of licensed qualities, that the shopper can rely on. Cross Bred Wool has now hit a six year low, coupled with China and India defaulting $\$ 45$ Million on contracts in the past twelve months.

Why can't we find, develop and encourage more highly differentiated markets than these commodity ones? The current 'Fernmark" is certainly a step in the right direction to differentiate our wool. However it is only the beginning to establish the state of origin. The wool from New Zealand as yet still does not have a distinct personality. Its associations need to be attached to more than countryside.

Is it softness in the growing world of technology? Should it become the counterpoint of nature in the high-tech home of tomorrow? Positioning wool to pamper the prosperous is surely a better route, than selling it to craft and commodity users in the third world. The resulting land based political structures we now have as a result of all this argument have become finely tuned forms of commercial détente, where effectively the status quo is carefully maintained. It is impossible to take a long term view, whilst structures are power and ownership based in their design and make-up rather than strategy based.

Look carefully at any electoral speech and its content will always be about structures, representation and industry ownership. Virtually nothing about food fashion or international marketing. They seem always devoid of new thought. When we start with some of the worlds finest raw material, reduce it to a humble cheddar, ship it to the US, then re-process into thin slices for a Cheeseburger, it seems to me as deplorable as taking the very best Chateaux Margaux grapes and fermenting them into a basic cooking vinegar.

When you go to the region of Parma in Italy, home of the world famous parmesan cheese, you find zero grazing in that the farmer is out cutting grass, when he can, buying supplements in and bringing it to the cow in a covered barn. I think I would prefer the Parmesan equivalent from those healthy free range cows, I saw on the way here today, if it were available.

In the development of the Cervena marketing strategy, we studied at great length issues of producer ownership and exporter energy; trying to integrate their individual wishes into a compatible marketing strategy was not easy.

I became interested in other fellowship models, such as in the Champagne district in France, London Guild structures in silver and diamonds and the Committee Colbert Association of luxury goods manufacturers in France. How was it, that for many years, these groups without legislation had managed even as arch competitors to position their industry and product category so effectively? They didn't seem to have procurement wars over grape-juice to make their Champagne.

Instead of thinking you can control plant material, consider the wealth you created in unregistered names like Kiwifruit, Braeburn and Royal Gala, which sadly you now share with others. Registered Brands and the intellectual property rights vested in a variety name are of no value, unless underpinned by an appellation or integrity agreement between growers.

New Zealand's greatest asset is its landbased wealth and growing intellect in international business. And yet, the two as yet don't know each other anywhere near well enough. Our primary sector leaders are a kind of 'secular priesthood' and their bureaucrats spend most of their efforts manufacturing consent. Its time to examine both the faith and those who propagate it in this sector, the engine of our economy.

Forty-five percent of the world's population now lives in cities, a proportion, which is rising rapidly. The fastest growing cities are in the developing world, some of which are on our doorstep. China alone has 95 cities with populations in excess of 1 million. By 2020, it is predicted there will 200 million middle class Chinese.

In an increasing world for most people of concrete, glass and busy train stations, there 
is a growing appreciation and hankering for things that are natural. Food, textiles, soft adventure holidays. 'Always been there!' some might say. 'Yes', the difference and this is very new, is that people want them, but not at a cost to nature.

The growing value of realness spells a very bright future for primary industry. Setting out to capture it, requires new skills and insights. Consider those beautiful ads' on TV for food: Happy couples, crisp apples on a summer's morning, ... aahhh the freshness. The visual journey along the supermarket shelves, stunning pictures and product claims. Farm fresh, happy hens, pure fruit, pest free! Exactly who says so and anyway, just how happy are those hens?

You see, now, we can brighten the cheeks up digitally and improve the bloom on a peach. We can green up the meadow in a butter story, even add a few daisies and clean up the cow's back-end, all in a design studio. Increasingly, we live in a visual age of story telling and as the credibility of product claims are stretched, then so it seems does the value of realness go up. Consider the price of true freshness and how its gone up in recent years. Chilled, tender farm assured natural venison, now known as Cervena, the price of fresh snapper, sushi style, free range eggs.

There is a growing number of discerning shoppers, quite prepared to pay for authentic product values, which they can rely on and truly enjoy. For over fifteen years now, as a marketing and Brand strategist, my work with a wide range of New Zealand food and beverage producers, has been without exception an attempt to re-position products characterised as commodities.

In every case study, be it wine, lamb, venison or seafood, the key ingredient value on which to create a turning point, has been quality. Not simply smoother words or better pictures, rather a real commitment to producing, delivering unique flavours, freshness and the accompanying joyful "recipied" moment of sheer pleasure.

There are still emotional extras and there need to be; however, increasingly such claims have to be underpinned by facts. Facts, which supermarket buyers, chefs and a growing number of consumer shoppers actively seek. Spray residues, preservatives, artificial colouring, tenderness, animal friendly, the list is growing in the wake of BSE scares and recently discovered issues of diet and nutrition.

Changing global consumer trends in affluent markets in terms of: ageing populations; heart consciousness; food safety issues; green consumers; smaller households; and increased leisure times, all present exciting new product opportunities.

In this context, the market scene of the new decade will be influenced more strongly by the concerns for personal health, animal welfare, and the well-being of the countryside. New Zealand's present vote of confidence from the rest of the world, in terms of a clean green environment, currently gives it a small window in history on which to capitalise and re-position many of our products.

Primary sector companies should encourage a premium supply relationship in a back to back marketing strategy, aimed at the top shelf. Many of our structures and supply arrangements take an averaging approach. It appears to me, there are not enough options to reward excellence.

Growers need to choose their markets, then pick the exporting company that will take them there. Retailers and exporting companies need to pick their suppliers, who will support their premium strategies. Above all, the old culture of fundamental pessimism has to be killed off forever. There is a mindset change needed in our land-based industries. The creation of new operating cultures with a shared positive outlook, being worked on steadily for the long haul. The farmers' pessimistic accountant and banker will be of little help. "Play one off against the other! Get the best deal on the day", they will say, never considering tomorrow's profit on a more long term consistent basis.

There are a whole range of environmental care projects around the world with similar ideas to Project 98. They start well, often providing successful political or networking platforms for individuals or companies. However, when the real funding is needed to power up the marketing strategy, the will seems sapped and they become another earnest licensing authority with a shoestring budget.

New Zealand is already an Eco-Label; however, our conditions for use of this label should be more than just citizenship. In future our current thresholds of hygiene and 
safety will not be enough. They may give us access to markets, but not access to the hearts and minds of the high margin customers in those markets. There are many new quality thresholds yet to be realised. New thresholds such as tenderness, colour, texture, softness, sustainability, animal and even human rights upon which we will be judged.

Gaining commitment at various levels in a primary industry is difficult. For those industries that advance to these new fellowship systems I have no doubt of their success, based on real strategic product advantages and not simply slick veneers. New alliances are needed to achieve this where the retailer or restaurateur is prepared to make an effort to help position or even re-position the product at better price points. No grower or farmer will buy into these strategies unless they can see an improved return. The word label suggests a sticker on a fruit item. Rather, we should be thinking of an Eco-Brand: a complete commitment from all those participants in the value chain.

So what about the researchers and scientists? Yes, they too can participate in this wealth creation process, by creating competitive advantage selectively with those partners they believe will achieve premiums from their scientific efforts and not go out and discount their valuable contribution. It distresses me to hear politicians beating MAF Quality Management up and threatening to pull the bungs outs.

Singapore has an international image for being tough on perceived threats to its society, be it drug-usage, littering or long hair. The world knows where Singapore stands. New Zealand needs a reputation for defending what it holds most dear. Not that our welcome tobona fide travellers is any less warm, but it has to be conditional. MAF needs a new image, one of a playing coach from plate to plough, and not a border policeman. Many organisations represented here today fail to see the contribution to the bottom line they can make.

The cost of defending the Green Oasis can more than be recovered in higher returns given your scientific work can be shaped into a competitive product advantage.

Out there is a farm, which most of us have never ever considered as a symbol of an extractive economy.

We have been doing more for less, because we have all been obsessed with production and processing efficiency, as opposed to meal options and dining experiences. Obsessed with staple and micron, as opposed to the romance and sensuality of New Zealand Wool. The greatest national asset we have, is our land. It is fundamental to the New Zealand economy.

These big butch industries we call agriculture and horticulture, in my view, up till now, could more aptly be described as land mining. Their male dominated management and political structures have struggled to understand a world, where virtually all the consumer decisions are taken by women. We have marginalised most of our creative people away from this major economic engine of New Zealand. Many of its Senior Executives do not respect the relationship between creativity and wealth generation. They seem driven by an obsession to improve capability in production and processing, as opposed to marketing.

The story of New Zealand, which to date has refined the commodity business: We have a magnificence of natural resources. In Japanese terms, we would be considered rich. How best can we wisely work with nature in a new kinship of sustainability? We are people that will always be here; our love of the land and these endeavours will be the mother of our new invention. Instead of feeling the rug is being pulled from under us, we need to learn to dance on a shifting carpet. How best can we shift from agri-culture and horti-culture to a fashion, tourism and food-culture?

Keywords: Marketing, ecolabelling, consumer, environmental 